Acta Theriologica 45, Suppl. 1: 69-78, 2000.

PL ISSN 0001-7051

\title{
Reproductive performance in two hybrid zones between chromosome races of the common shrew Sorex araneus in Poland
}

\author{
Agata BANASZEK, Stanisław FEDYK, Katarzyna A. SZAŁAJ \\ and Włodzimierz CHĘTNICKI
}

\begin{abstract}
Banaszek A., Fedyk S., Szałaj K. A. and Chętnicki W. 2000. Reproductive performance in two hybrid zones between chromosome races of the common shrew Sorex araneus in Poland. [In: Evolution in the Sorex araneus group: Cytogenetic and molecular aspects. J. B. Searle and J. M. Wójcik, eds]. Acta Theriologica 45, Suppl. 1: 69-78.
\end{abstract}

We studied the reproductive performance of common shrews from two hybrid zones in Poland: one between the Drnholec and Łcgucki Młyn chromosome races and another between the Guzowy Młyn and Łęgucki Młyn races. In both hybrid zones, reproductive output was low in populations where the frequency of CHV-forming hybrids was greater then $10 \%$. The presence of RIV-forming and CHIV-forming hybrids had no effect on reproductive performance.

Institute of Biology, University of Białystok, Świerkowa 20B, 15-950 Bialystok, Poland, e-mail: banaszek@cksr.ac.bialystok.pl

Key words: Sorex araneus, complex heterozygotes, hybrid zone, fertility

\section{Introduction}

In mammals, chromosomal heterozygosity caused by the presence of Robertsonian $(\mathrm{Rb})$ metacentrics usually leads to meiotic disturbances which may cause reduced fertility or even sterility (Searle 1993). Studies on mice, man and other mammals indicate that trivalents and larger complexes at meiosis have a greater tendency for aberrant pairing at pachytene and higher non-disjunction levels than normal bivalents. As a result $\mathrm{Rb}$ heterozygotes have increased level of germ cell death and higher numbers of aneuploid, lethal embryos (Searle 1993).

However, this does not hold to a similar degree for all mammals showing $\mathrm{Rb}$ variation. An interesting case is the common shrew Sorex araneus Linnaeus, 1758 with intrapopulational $\mathrm{Rb}$ polymorphism and interpopulational $\mathrm{Rb}$ variation expressed as numerous races with differing combinations of $\mathrm{Rb}$ metacentrics. In the common shrew the fertility of simple Rb heterozygotes (ie those that produce trivalents at meiosis) is only slightly reduced when compared with homozygous individuals. This difference is difficult to detect in the small samples that are 
possible to collect from natural populations (for review see Searle 1993). In hybrid zones between chromosome races of the common shrew, complex heterozygotes with meiotic complexes longer than a trivalent are present. Their fertility is important to establish, as hybrid zones in the common shrew are often considered as tension zones maintained by antagonistic forces of selection against hybrids and dispersal of individuals. Collection of mature shrews with karyotypes of complex heterozygotes is particularly difficult, as the frequency of such individuals is reduced in many hybrid zones by selection (Fedyk 1986, Searle 1986, Fedyk et al. 1991). Hence, the basic assumption of the dynamics of the common shrew hybrid zones, ie the pressure of selection against hybrids due to their reduced fertility, is still merely hypothetical. However, it has to be stressed that the chromosomal structure of some hybrid zones strongly argues for this assumption (for review see Searle 1993, Searle and Wójcik 1998).

In this paper we present the results of a study on reproductive performance in two hybrid zones in Poland: one between the Drnholec (Dn - specific metacentrics $h i, k o, g m, n r)$ and Łęgucki Młyn ( $\mathrm{Lg}-h k, i o, g r, m n)$ chromosome races (Fedyk et al. 1991, Szałaj et al. 1995, Fedyk 1995, Fedyk et al. 2000) and another between the Guzowy Młyn (Gu - hi, ko, gr, $m n$ ) and Łg races (Banaszek 1994, 1997) (Fig. 1). The chromosome arms in the karyotypes are labelled according to Searle et al. (1991). In both hybrid zones, hybrids with four-element ring configurations (RIV) and fourand five-element chain configurations (CHIV and CHV) at meiosis are present.

Studies on hybrid fertility in the common shrew have concentrated on pachytene pairing, meiotic nondisjunction and germ-cell death (for review see Searle 1993). The values of these several parameters have been compared with values characteristic for individuals of the pure races (homozygotes and simple $\mathrm{Rb}$ heterozygotes). In general, the studies have indicated that meiosis is less regular in the hybrids than the pure race individuals. But the differences between RIV-forming hybrids and pure race individuals were found to be insignificant and the fertility of RIV-forming hybrids is probably not reduced (Narain and Fredga 1997, Banaszek et al. 2000). Chain-forming complex heterozygotes, both CHIV and CHV, suffer the greatest germ-cell loss in comparison with homozygotes, simple Rb heterozygotes and RIV hybrids. However, the estimated level of germ-cell death is probably not sufficient to influence substantially the fertility of these males (Banaszek et al. 2000). Although the available data on CHIV-forming hybrids is scarce, it seems that meiotic disturbances caused by the presence of 4-element chains are as insignificant as in the case of 4-element ring configurations (Searle 1988, 1993). On the other hand, hybrids with $\mathrm{CHV}$ configurations differ more significantly from homozygotes with respect to the level of nondisjunction. Nondisjunction in homozygotes is about 3\% (Mercer et al. 1991) while in CHV-forming hybrids the level of nondisjunction was estimated as $9.3 \%$ on the basis of 108 metaphase spreads from two individuals (A. Banaszek, S. Fedyk, K. A. Szałaj, W. Chętnicki, unpubl.). It is probable that in both hybrid zones only CHV-forming hybrids have lowered fertility due to production of aneuploid gametes. 


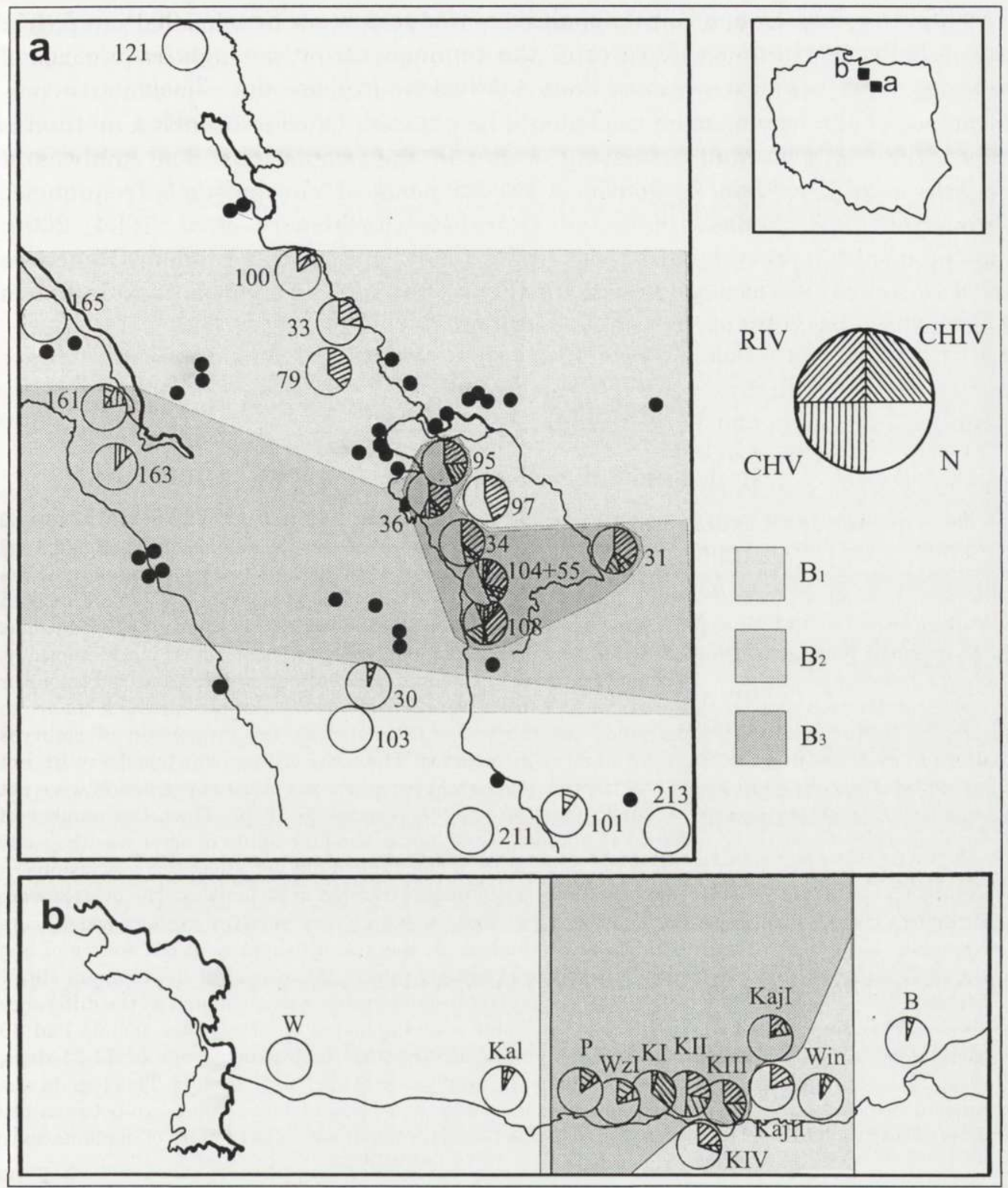

Fig. 1. Percentage occurrence of RIV-, CHIV- and CHV-forming hybrids and individuals without these chromosome complexes in the Drnholec/Lęgucki Młyn hybrid zone (a) and Guzowy Młyn/Lęucki Młyn hybrid zone (b) of Sorex araneus in northern Poland. The subzones $\mathrm{B}_{1}, \mathrm{~B}_{2}$ and $\mathrm{B}_{3}$ in the $\mathrm{Dn} / \mathrm{kg}$ hybrid zone and the subzones $B_{1}$ and $B_{3}$ in the $\mathrm{Gu} / \mathrm{kg}$ hybrid zone are shown. All the populations studied in the $\mathrm{Dn} / \mathrm{Lg}$ hybrid zone (black circles) and code numbers following Fedyk (1995) and Szałaj et al. (1995) are indicated. The abbreviations of the names of populations in the $\mathrm{Gu} / \mathrm{Lg}$ hybrid zone follow those in Banaszek (1994, 1997). Percentage occurrence of RIV-, CHIV- and CHV-forming hybrids and individuals without these chromosome complexes $(\mathrm{N})$ are calculated for the populations where pregnant females were collected. 
This study was carried out to measure reproductive output in pooled samples of populations. We assumed that in the populations with rather high frequencies of hybrids, most matings involved such hybrids and hence the reproductive performance of the whole population should be reduced. Of course, such a method is appropriate only if random mating occurs in the populations. The analysis of genetic equilibrium in populations on the basis of chromosome frequencies (Banaszek 1994, Fedyk 1995) and allozymes (Ratkiewicz et al. 1994, 2000) indicated that, in both hybrid zones under study, mating was random. Hence we tried to find if potentially lowered fertility of any kind of hybrids is reflected in reproductive performance of the populations.

\section{Material and methods}

\section{Animals and reproductive characteristics}

Forty-seven pregnant females were collected between 1989 and 1993 in the Dn/ $\mathrm{kg}$ hybrid zone - 30 in June and 17 in July. In the Gu/Lg hybrid zone 29 pregnant females were collected in 1992 and 1993 (July only). In order to measure the reproductive output of the populations the following parameters were scored: number of embryos and number of embryos undergoing regression per female in both hybrid zones and number of eggs ovulated and number of implanted embryos in the $\mathrm{Gu} / \mathrm{Lg}$ hybrid zone. In all pregnant females examined, the number of implanted embryos was determined macroscopically. Embryos showing any signs of tissue breakdown or with a placenta without an intensive, red colour or of a size considerably smaller than the other embryos were considered dead or not having a chance to survive to parturition. Postimplantation mortality was estimated as the proportion of embryos undergoing regression out of the total number of embryos. The uteri of pregnant females were not analyzed histologically, thus it was possible that some embryos at the late stage of regression were not detected. Such embryos appear as small lumps of detritus (Tarkowski 1956). Thus, the number of embryos undergoing regression might be underestimated, but as the probability of error was the same across all groups of females compared, the inaccuracy of the method did not affect the conclusions.

In the $\mathrm{Gu} / \mathrm{kg}$ hybrid zone the number of corpora lutea was counted in 20 females. The ovaries were preserved in Bouin's fixative and the whole ovary was cut into $10 \mu \mathrm{m}$ paraffin sections which were stained with haematoxylin and eosin. Each corpus luteum was taken to represent the source of one ovum, as it is known that polyovular follicles are extremely rare in the ovaries of the common shrew (Tarkowski 1957, Wallace and Searle 1994). Preimplantation mortality was calculated as the difference between the number of corpora lutea and the number of implanted embryos. One female had 10 corpora lutea and only 2 embryos at the 7th developmental stage (approximate age of 20-21 days, Šterrba 1977), both undergoing regression. This was the only case of a whole litter loss. This female was not included in the analysis of preimplantation mortality, as in this case the difference between the number of corpora lutea and the number of implanted embryos might not reflect failure of implantation.

\section{Data analysis}

In order to discriminate between the effects of three kinds of hybrids on reproductive performance of the populations, we tested three different hypotheses: (1) First we assumed that the presence of hybrids of any kind may influence the reproductive output in the populations and we divided both hybrid zones into two subzones depending on the frequency of hybrids in the population. The subzone $A_{1}$ included the populations of pure races from the borders of the hybrid zones and populations with low frequencies of hybrids and the subzone $B_{1}$ included populations with more than $10 \%$ of any kind of hybrids (RIV-, CHIV- and CHV-forming hybrids) (Fig. 1). (2) Then we assumed that only chain-forming hybrids may influence reproductive output. In this case the subzone $\mathrm{A}_{2}$ included pure race populations, the populations with low frequencies of hybrids and the populations with high frequencies 
of RIV- forming hybrids. The subzone $\mathrm{B}_{2}$ comprised the populations with more than $10 \%$ chain-forming hybrids, both CHIV and CHV (Fig. 1). This criterion was not used for the Gu/Lg hybrid zone. (3) Finally we assumed that only CHV-forming hybrids influence reproductive performance in the populations. The subzone $\mathrm{B}_{3}$ included all populations with a frequency of $\mathrm{CHV}$-forming hybrids higher than $10 \%$ and the subzone $\mathrm{A}_{3}$ included pure race populations, the populations with low frequencies of hybrids and the populations with high frequencies of RIV- and CHIV-forming hybrids. In the populations belonging to the $\mathrm{B}_{3}$ subzone the frequency of RIV-and CHIV-forming hybrids varied from high frequencies to an absence of those types of hybrids (Fig. 1). The $A_{3}-B_{3}$ subdivision was used for the $\mathrm{Gu} / \mathrm{Lg}$ hybrid zone, but the $\mathrm{A}_{2}-\mathrm{B}_{2}$ subdivision was not, because CHIV-forming hybrids were extremely rare in that zone (Banaszek 1994).

\section{Numbers of breeding females and immature shrews}

The numbers of breeding females (pregnant or lactating) and young shrews present in the hybrid zones in July were compared between the subzones. The number of trapnights for each group of populations was taken into consideration.

\section{Statistics}

Differences in reproductive performance were tested with the Mann-Whitney test at $p=0.05$. The differences in numbers of breeding females and immature shrews per trap night were compared with a Chi-square test for homogeneity. Expected numbers of shrews in the subzones were calculated from the total number of females and immatures collected in the hybrid zone divided proportionally to the number of trapnights for the subzone.

\section{Results}

We did not find any statistically significant differences in the number of implanted and live embryos, the level of the post-implantation mortality or numbers of shrews per trap night between subzones $A_{1}$ and $B_{1}$ in either hybrid zone. Similarly, there were no differences between subzones $\mathrm{A}_{2}$ and $\mathrm{B}_{2}$ in the $\mathrm{Dn} / \mathrm{Lg}$ hybrid zone. However, we found differences between the subzones $\mathrm{A}_{3}$ and $\mathrm{B}_{3}$, ie on the basis of the frequency of CHV-forming hybrids, and this will be described in detail.

\section{The Dn/Lg hybrid zone}

The number of implanted and live embryos per female was significantly higher in June ( 6.8 and 6.6 respectively) than in July (5.5 and 5.4 respectively) $(Z=2.677$, $p=0.007$ and $Z=2.609, p=0.009$, respectively). The number of implanted embryos per female was lower in the $B_{3}$ subzone than in the $A_{3}$ subzone but the difference was not statistically significant $(Z=1.750, p=0.080)$ (Table 1$)$. The level of postimplantation mortality was significantly higher in the females from the $\mathrm{B}_{3}$ subzone $(Z=2.272, p=0.023)$ (Table 1$)$, and there was no effect of the month of capture on the level of postimplantation mortality $(Z=0.322, p=0.748)$. The number of live embryos per female was significantly lower in the $\mathrm{B}_{3}$ subzone $(Z=$ $2.138, p=0.032$ ) (Table 1 ). The number of breeding females and immature shrews did not differ significantly between the $\mathrm{A}_{3}$ and $\mathrm{B}_{3}$ subzones $\left(\chi^{2}=0.95, \mathrm{df}=1,0.5>\right.$ $p>0.3 ; \chi^{2}=0.00, \mathrm{df}=1, p>0.99$, respectively) (Table 2 ). 
Table 1. Mean ( \pm SE) numbers of implanted and 'live' embryos per female and postimplantation mortality in the subzones $\mathrm{A}_{3}$ and $\mathrm{B}_{3}$ of the $\mathrm{Dn} / \mathrm{Lg}$ and $\mathrm{Gu} / \mathrm{Lg}$ hybrid zones of Sorex araneus. ${ }^{*}-$ the proportion of resorbed embryos out of total number of embryos.

\begin{tabular}{lccccc}
\hline \multicolumn{1}{c}{ Hybrid zone: } & \multicolumn{2}{c}{$\mathrm{Dn} / \mathrm{Lg}$} & & & $\mathrm{Gu} / \mathrm{Lg}$ \\
\cline { 2 - 5 } \cline { 5 - 5 } \multicolumn{1}{c}{ Subzone: } & $\mathrm{A}_{3}$ & $\mathrm{~B}_{3}$ & & $\mathrm{~A}_{3}$ & $\mathrm{~B}_{3}$ \\
\hline Number of pregnant females & 36 & 11 & & 19 & 10 \\
Number of implanted embryos & $6.7 \pm 0.2$ & $5.4 \pm 0.7$ & & $6.3 \pm 0.2$ & $4.9 \pm 0.6$ \\
Number of 'live' embryos & $6.6 \pm 0.2$ & $5.0 \pm 0.7$ & & $5.9 \pm 0.3$ & $4.4 \pm 0.6$ \\
Mortality* & 0.01 & 0.08 & & 0.07 & 0.10 \\
\hline
\end{tabular}

\section{The Gu/Lg hybrid zone}

We found a significant difference in the number of implanted and live embryos per female between the subzones $(Z=2.040, p=0.041$ and $Z=2.043, p=0.041$ respectively). The number of embryos per female was lower in the $B_{3}$ subzone than in the $\mathrm{A}_{3}$ subzone (Table 1). Although the level of postimplantation mortality was higher in the $B_{3}$ than in the $A_{3}$ subzone, the difference was not statistically significant $(Z=0.516, p=0.606$ ) (Table 1 ). There was no significant difference in the number of corpora lutea in females from the $A_{3}(n=14$, mean of 6.6 corpora lutea per female) and $\mathrm{B}_{3}$ subzones $(n=5$, mean of 7.0$)(Z=0.631, p=0.528)$. The level of preimplantation mortality was higher in the $B_{3}$ subzone (1.4 wasted ova per female) than in the $A_{3}$ subzone (0.4), but the difference was not statistically significant $(Z=1.740, p=0.082)$. There was no difference in number of breeding females collected in the $A_{3}$ and $B_{3}$ subzones $\left(\chi^{2}=3.13\right.$, $\left.\mathrm{df}=1,0.1>p>0.05\right)$, while the number of immature shrews caught in the $B_{3}$ subzone was significantly lower than in the $\mathrm{A}_{3}$ subzone $\left(\chi^{2}=9.81, \mathrm{df}=1, p<0.01\right.$ ) (Table 2).

Table 2. Numbers of breeding females and young shrews collected in July in the subzones $A_{3}$ and $B_{3}$ in the $\mathrm{Dn} / \mathrm{Lg}$ and $\mathrm{Gu} / \mathrm{Lg}$ hybrid zones of Sorex araneus.

Subzone No. of trapnights No. of breeding females No. of young shrews

\begin{tabular}{lccc} 
& \multicolumn{3}{c}{ The Dn/ Łg hybrid zone } \\
$\mathrm{A}_{3}$ & 4249.5 & 19 & 236 \\
$\mathrm{~B}_{3}$ & 2403.5 & 7 & 134 \\
& & The Gu/Lg hybrid zone & \\
& & 27 & 162 \\
$\mathrm{~A}_{3}$ & 2829 & 24 & 167 \\
$\mathrm{~B}_{3}$ & 4112 & &
\end{tabular}




\section{Discussion}

The fertility of an individual is very difficult to estimate and ultimately it can be expressed in the number of young raised, ie breeding success. It would be desirable to compare the numbers of embryos and young raised in controlled matings. However, laboratory breeding would be necessary for such study, which is rather a difficult and time consuming task in the common shrew (Mercer and Searle 1994). Some information may be obtained from natural populations, by comparing the number of embryos per females of known karyotypes. Such a study was conducted in the Oxford/Hermitage hybrid zone in England (Searle 1990). Number of embryos per female and prenatal losses were compared between homozygous and simple $\mathrm{Rb}$ heterozygous females. Although the nondisjunction level was found to be higher in female simple $\mathrm{Rb}$ heterozygotes, the fertility of homozygous and simple $\mathrm{Rb}$ heterozygous females was not clearly differentiated, probably thanks to a greater number of ovulations in heterozygotes. Moreover it was concluded that the average fecundity of females from the hybrid zone area was not obviously lowered in comparison with females from other areas either areas of polymorphism or areas of monomorphism (Searle 1990). Thus, the presence of complex heterozygotes in the Oxford/Hermitage hybrid zone seems to have no clear effect on the reproductive performance of shrews from the hybrid area although some of the males that sired the embryos could be complex heterozygotes.

In our study we could not estimate the fertility of karyotyped females, as in spite of many years of trapping, our samples of karyotyped females were too small for statistical analysis. Hence we tried to evaluate reproductive performance on the basis of whole populations. Our results confirm that there is no effect of RIV-forming hybrids on reproductive performance of the populations. We did not find any differences in number of embryos, the level of embryo mortality and density of shrews between the subzones $A_{1}$ and $B_{1}$ when the populations with high frequencies of RIV-forming hybrids were included in the $\mathrm{B}_{1}$ subzone (Fig. 1). Similarly, the presence of CHIV-forming hybrids did not influence reproductive performance in the $\mathrm{Dn} / \mathrm{Lg}$ hybrid zone. The subzone $\mathrm{B}_{2}$ with populations bearing high frequencies of CHIV-forming hybrids did not differ from the subzone $\mathrm{A}_{2}$ (Fig. 1). Statistically significant differences in the breeding parameters were found only between the populations with high frequencies of CHV-forming hybrids and all the other populations in both hybrid zones (Table 1, Fig. 1).

In the $\mathrm{Gu} / \mathrm{tg}$ hybrid zone the number of implanted and live embryos was significantly lower in the populations with high frequencies of CHV-forming hybrids (Table 1). The difference in the number of implanted embryos presumably resulted from preimplantation mortality, although its direct analysis did not reveal significant differences between the subzones, perhaps due to small sample size. In the $\mathrm{Dn} / \mathrm{Lg}$ hybrid zone there was no difference in the number of implanted embryos between the $A_{3}$ and $B_{3}$ subzones (Table 1). However, the level of the postimplantation mortality of embryos was significantly higher in the populations with 
high frequencies of CHV-forming hybrids (Table 1), and the number of live embryos was in consequence lower. Hence, although the difference was not as clear as in the $\mathrm{Gu} / \mathrm{Lg}$ hybrid zone, the reproductive performance was also lower in the $\mathrm{B}_{3}$ subzone than in the $\mathrm{A}_{3}$ subzone for the $\mathrm{Dn} / \mathrm{\iota g}$ hybrid zone.

Moreover we found that in July breeding females were evenly distributed in the $A_{3}$ and $B_{3}$ subzones of the $\mathrm{Gu} / \mathrm{Lg}$ hybrid zone but the density of immature shrews was lower in the $\mathrm{B}_{3}$ subzone (Table 2). In the Dn/ $\mathrm{Eg}$ hybrid zone, females breeding in July were also evenly distributed between the $A_{3}$ and $B_{3}$ subzones but, in contrast to the $\mathrm{Gu} / \mathrm{Lg}$ hybrid zone, there were no differences in density of young shrews (Table 2). Thus, despite some differences between the hybrid zones, the populations with the highest percentage of CHV-forming hybrids have lowered reproductive output in both hybrid zones in comparison with all the other populations from the hybrid zones and adjoining areas. It confirms our supposition that only CHV-forming hybrids have lowered fertility in both hybrid zones. Given this result it is interesting why the shrews from the Oxford/Hermitage hybrid zone did not show any reduction of the reproductive output relative to the other areas (Searle 1990). There are two possible explanations: (1) the frequencies of complex heterozygotes, especially CHV-forming hybrids, are too low due to the acrocentric peak (Searle 1986), to have any effect on reproductive performance of populations; (2) the effect of CHV-forming hybrids can be seen only in some populations with the highest frequencies of these hybrids and it cannot be detected when the group of shrews from the area of the hybrid zone is not divided according to this criterion.

Considering further the situation in Poland, we believe that the effect of $\mathrm{CHV}$-forming hybrids in the $\mathrm{Dn} / \mathrm{Lg}$ and $\mathrm{Gu} / \mathrm{Lg}$ hybrid zones is so strong that it is difficult to ascribe it totally to chromosomal meiotic problems only. The differences in number of implanted and live embryos, and in number of breeding females and immature shrews, between the $A_{3}$ and $B_{3}$ subzones are substantial, especially for the $\mathrm{Gu} / \mathrm{Lg}$ hybrid zone (Table 1,2 ). However, the populations of the $\mathrm{B}_{3}$ subzone are situated in the most unfavourable habitats in the whole hybrid zone (A. Banaszek, pers. obs.). It is known that habitat may influence the level of prenatal mortality in the common shrew (Tarkowski 1956). According to hybrid zone theory, the presence of the populations with the most unfit individuals in the worst habitats may not be accidental. Hybrid zones are attracted into density traps ie the areas where the lowest numbers of individuals can survive (Hewitt 1988). Hence, the decrease in number of live embryos and number of pregnant females and immature shrews in the $B_{3}$ subzone caused by environmental conditions is still the effect, although not directly, of the presence of CHV-forming hybrids. The situation is not as clear for the Dn/ $\mathrm{Lg}$ hybrid zone. The habitats throughout the hybrid zone appear to be comparable. Hence, it is less probable than in the $\mathrm{Gu} / \mathrm{Lg}$ hybrid zore that breeding in the $\mathrm{B}_{3}$ subzone is influenced by environmental conditions.

Acknowledgements: We are grateful to M. Kozioł for her help in laboratory work and Dr M. Rakiewicz for his help in the field work. We thank Dr M. Konarzewski for valuable comments and help with revision of the English style of the manuscript. This work was supported by grants 6P204 03405 and 6P04C 03515 of the State Committee for Scientific Research (KBN). 


\section{References}

Banaszek A. 1994. The structure of the contact zone between chromosomal races Drużno and Łęucki Młyn in the common shrew (Sorex araneus) in north-eastern Poland - preliminary results. [In: The cytogenetics of the Sorex araneus group and related topics: Proceedings of the ISACC's Third International Meeting. J. Zima, J. B. Searle and M. Macholan, eds]. Folia Zoologica 43, Suppl. 1: 11-19.

Banaszek A. 1997. [Chromosome variation and breeding parameters of the common shrew (Sorex araneus L., 1758) in an interracial hybrid zone]. Ph D Thesis, University of Warsaw: 1-84. [In Polish]

Banaszek A., Fedyk S., Szałaj K. A. and Chętnicki W. 2000. A comparison of spermatogenesis in homozygotes, simple Robertsonian heterozygotes and complex heterozygotes of the common shrew (Sorex araneus). Heredity 84 , in press.

Fedyk S. 1986. Genetic differentiation of Polish populations of Sorex araneus L. II. Possibilities of gene flow between chromosome races. Bulletin of the Polish Academy of Sciences, Biological Sciences 34: 161-171.

Fedyk S. 1995. [Geographic chromosomal differentiation and hybrid zones between chromosome races of Sorex araneus in north-eastern Poland]. Dissertationes Universitatis Varsoviensis 439, Białystok: 1-125. [In Polish]

Fedyk S., Banaszek A., Cichomska A., Chętnicki W. and Szałaj K. A. 2000. Reassessment of the range of the Drnholec race: the studies on meiosis in Sorex araneus hybrids. [In: Evolution in the Sorex araneus group: Cytogenetic and molecular aspects. J. B. Searle and J. M. Wójcik, eds]. Acta Theriologica 45, Suppl. 1: 59-67.

Fedyk S., Chętnicki W. and Banaszek A. 1991. Genetic differentiation of Polish populations of Sorex araneus L. III. Interchromosomal recombination in a hybrid zone. Evolution 45: 1384-1392.

Hewitt G. M. 1988. Hybrid zones - natural laboratories for evolutionary studies. Trends in Ecology and Evolution 3: 158-167.

Mercer S. J. and Searle J. B. 1994. Captive breeding of the common shrew (Sorex araneus) for chromosomal analysis. [In: Advances in the biology of shrews. J. F. Merritt, G. L. Kirkland Jr and R. K. Rose, eds]. Special Publication of Carnegie Museum of Natural History No. 18, Pittsburgh: 271-276.

Mercer S. J., Searle J. B. and Wallace B. M. N. 1991. Meiotic studies of karyotypically homozygous and heterozygous male common shrews. [In: The cytogenetics of the Sorex araneus group and related topics: Proceedings of the ISACC's Second International Meeting. J. Hausser, ed]. Mémoires de la Société Vaudoise des Sciences Naturelles 19: 33-43.

Narain Y. and Fredga K. 1997. Meiosis and fertility in common shrews, Sorex araneus, from a chromosomal hybrid zone in central Sweden. Cytogenetics and Cell Genetics 78: 253-259.

Ratkiewicz M., Banaszek A. and Łobodzińska J. 1994. Isoenzyme variation in the common shrew (Sorex araneus) from the hybrid zone between chromosomal races Drużno and Łcgucki Młyn: preliminary results. [In: The cytogenetics of the Sorex araneus group and related topics: Proceedings of the ISACC's Third International Meeting. J. Zima, J. B. Searle and M. Macholan, eds]. Folia Zoologica 43, Suppl. 1: 21-28.

Ratkiewicz M., Supruniuk J., Fedyk S., Banaszek A., Chętnicki W. and Szałaj K. A. 2000. Genetic differentiation and gene flow between the Drnholec and Łcgucki Młyn chromosome races of the common shrew Sorex araneus in northern Poland. [In: Evolution in the Sorex araneus group: Cytogenetic and molecular aspects. J. B. Searle and J. M. Wójcik, eds]. Acta Theriologica 45, Suppl. 1: 79-91.

Searle J. B. 1986. Factors responsible for a karyotypic polymorphism in the common shrew, Sorex araneus. Proceedings of the Royal Society of London, Series B 229: 277-298.

Searle J. B. 1988. Selection and Robertsonian variation in nature: the case of the common shrew. [In: The cytogenetics of mammalian autosomal rearrangements. A. Daniel, ed]. Alan Liss, New York: 507-531. 
Searle J. B. 1990. A cytogenetical analysis of reproduction in common shrews (Sorex araneus) from a karyotypic hybrid zone. Hereditas 113: 121-132.

Searle J. B. 1993. Chromosomal hybrid zones in eutherian mammals. [In: Hybrid zones and the evolutionary process. R. G. Harrison, ed]. Oxford University Press, New York: 309-353.

Searle J. B., Fedyk S., Fredga K., Hausser J. and Volobouev V. T. 1991. Nomenclature for the chromosomes of the common shrew (Sorex araneus). [In: The Cytogenetics of the Sorex araneus group and related topics: Proceedings of the ISACC's Second International Meeting. J. Hausser, ed]. Mémoires de la Société Vaudoise des Sciences Naturelles 19: 13-22.

Searle J. B. and Wójcik J. M. 1998. Chromosomal evolution: The case of Sorex araneus. [In: Evolution of shrews. J. M. Wójcik and M. Wolsan, eds]. Mammal Research Institute, Polish Academy of Sciences, Białowieża: 219-268.

Štěrba O. 1977. Prenatal development of central European insectivores. Folia Zoologica 26: 27-44.

Szałaj K. A., Fedyk S., Banaszek A. and Chętnicki W. 1995. Maximization of the frequency of recombinants in the hybrid zone of Sorex araneus in northern Poland. Acta Theriologica 40: $225-236$.

Tarkowski A. K. 1956. Studies on reproduction and prenatal mortality of the common shrew (Sorex araneus L.) I. Foetal regression. Annales Universitatis Mariae Curie-Skłodowska, Sectio C 9: 387-429.

Tarkowski A. K. 1957. Studies on reproduction and prenatal mortality of the common shrew (Sorex araneus L.). II. Reproduction under natural conditions. Annales Universitatis Mariae Curie-Skłodowska, Sectio C 10: 177-244. [In Polish with English summary]

Wallace B. M. N. and Searle J. B. 1994. Oogenesis in homozygotes and heterozygotes for Robertsonian chromosomal rearrangements from natural populations of the common shrew, Sorex araneus. Journal of Reproduction and Fertility 100: 231-237.

Received 1 October 1999, accepted 30 March 2000. 